\title{
ASSESMENT OF THE ASSOCIATION BETWEEN QUALITY OF LIFE IN PATIENTS WITH ATRIAL FIBRILATION AND CARDIOVASCULAR OUTCOMES DURING THE ONE-YEAR FOLLOW-UP
}

\section{PROCENA POVEZANOSTI KVALITETA ŽIVOTA OBOLELIH OD ATRIJALNE FIBRILACIJE I KARDIOVASKULARNIH ISHODA TOKOM JEDNOGODIŠNJEG PRAĆENJA}

\author{
Ana Vlajković ${ }^{1}$, Matej Vilotijević1, Marija Polovina ${ }^{1,2}$
}

\begin{abstract}
${ }^{1}$ Univerzitet u Beogradu, Medicinski fakultet, Srbija
${ }^{2}$ Klinika za kardiologiju, Klinički centar Srbije, Beograd, Srbija

Correspondence: ana.vlajkovic1@gmail.com
\end{abstract}

Keywords:

atrial fibrillation,

quality of life,

questionnaire,

assessment of treatment

outcomes

\section{Abstract}

Introduction: Research evidence indicates that atrial fibrillation $(\mathrm{AF})$ could have a negative impact on the quality-of-life (QoL). AF symptom pattern and AF-related QoL have been associated with adverse cardiovascular outcomes.

Aim: The aims of the present study are to evaluate AF-related impact on QoL using the Atrial Fibrillation Effect on Quality-of-Life (AFEQT) questionnaire, and to assess the association of QoL with adverse cardiovascular outcomes during the 1-year follow-up.

Material and methods: An observational, cohort study that included AF patients treated at the Cardiology Clinic, Clinical Center of Serbia, willing to fill-in AFEQT questionnaire to assess the overall QoL (AFEQT score, 0 to 100) and QoL components: symptoms, daily activities, treatment concerns and treatment satisfaction. During the prospective 1-year follow-up, data on the following outcomes were collected: 1) major adverse cardiovascular outcomes - a combined endpoint, including: stroke/transient ischemic attack, myocardial infarction, percutaneous/surgical coronary revascularization, or cardiovascular death;2) hospitalization for heart failure.

Results: We included 202 AF patients (mean age: $64.5 \pm 12.4$ years; $62.9 \%$ men; $24.3 \%$ asymptomatic AF). The mean AFEQT score was $64.3 \pm 8.8$. There was a negative correlation between objective estimate of AF-related symptoms and AFEQT score (Spearman rho $=-0.489$, $\mathrm{P}<0.001$ ). During 1-year follow-up, major adverse cardiovascular outcomes occurred in $8.4 \%$ of patients and 3.5\% were hospitalized for heart failure. In a multivariate logistic regression model, controlling for clinical variables, treatment satisfaction score was significantly associated with major adverse cardiovascular outcomes (OR, 0.97; 95\%CI, 0.94-0.99, $\mathrm{P}=0.022$ ), while the overall AFEQT score was associated with heart failure hospitalizations (OR, 0.98; 95\%CI, 0.95-0.99; $\mathrm{P}=0.014$ ).

Conclusion: Our results indicate that AF has a negative impact on QoL. Better QoL as assessed by AFEQT score and higher treatment satisfaction are associated with reduced odds for adverse outcomes, which is relevant for clinical risk-stratification and appropriate treatment of AF patients. 
Vlajković A. et al. Assesment of the association between quality of life in patients with atrial fibrilation and cardiovascular outcomes during the one-year follow-up. MedPodml 2017, 68(3):8-16

\section{Sažetak}

Uvod: Istraživanja pokazuju da atrijalna fibrilacija (AF) može negativno da utiče na kvalitet života (QoL) i da karateristike simptomatske prezentacije AF, kao i njen uticaj na QoL mogu biti povezani sa nepovoljnim kardiovaskularnim ishodima.

Cilj: Ciljevi rada su da se primenom Atrial Fibrillation Effect on Quality-of-Life (AFEQT) upitika proceni QoL bolesnika sa AF i da se ispita povezanost QoL sa kardiovaskularnim ishodima tokom jednogodišnjeg kliničkog praćenja.

Materijal i metode: Opservaciona, kohortna studija u koju su uključeni bolesnici sa AF lečeni u Klinici za kardiologiju Kliničkog centra Srbije koji su prihvatili da popune AFEQT upitnik za procenu ukupnog QoL (AFEQT skor, 0 do 100) i 4 aspekta QoL - simptomi, ograničenja u dnevnim aktivnostima, zabrinutost zbog posledica lečenja i zadovoljstvo lečenjem. Tokom prospektivnog jednogodišnjeg praćenja evidentirani su ishodi studije: 1) značajni kardiovaskularni događaj - kombinovani ishod koji uključuje moždani udar/tranzitorni ishemijski atak, infarkt miokarda, perkutanu/hiruršku koronarnu revaskularizaciju ili kardiovaskularnu smrt, 2) hospitalizacija zbog srčane insuficijencije.

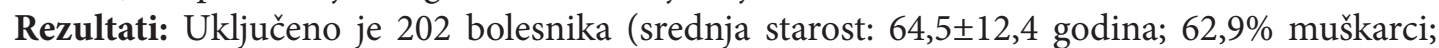
$24,3 \%$ asimptomatska AF). Srednja vrednost AFEQT skora je $64,3 \pm 8,8$. Pokazana je negativna korelacija između objektivne procene težine simptoma i AFEQT skora (Spearman rho $=$ $-0,489, \mathrm{p}<0,001)$. Tokom jednogodišenjeg praćenja značajan kardiovaskularni događaj je zabeležen kod 8,4\% ispitanika, a hospitalizacija zbog srčane insuficijencije je registrovana kod 3,5\%. U multivarijantnom regresionom modelu kontrolisanom za kliničke varijable, skor kojim je procenjeno zadovoljstvo terapijom bio je povezan sa značajnim kardiovaskularnim događajem (OR, 0,97; 95\%CI, 0,94-0,99; $\mathrm{P}=0,022$ ), dok je ukupni AFEQT skor bio povezan sa hospitaliza-

Ključne reči:

atrijalna fibrilacija,

kvalitet života,

upitnik,

procena ishoda lečenja cijom zbog srčane insuficijencije (OR, 0,98; 95\%CI, 0,95-0,99; $\mathrm{P}=0,014)$.

Zaključak: Rezultati istraživanja pokazuju da se AF nepovoljno odražava na QoL. Bolji QoL procenjen AFEQT skorom i veće zadovoljstvo pacijenata sprovedenim lečenjem su povezani sa manjom verovatnoćom nepovoljnih ishoda, što je od značaja u kliničkoj proceni rizika i sprovođenju odgovarajućih terapijskih mera kod bolesnika sa AF.

\section{Uvod}

Atrijalna fibrilacija (AF) je najčešći dugotrajni poremećaj srčanog ritma, prisutan kod oko $2 \%$ odraslih (1). Nezavisno od komorbiditeta, AF povišava rizik za nastanak tromboembolijskih komplikacija, srčane slabosti i smrtnog ishoda (2-5), a novija saznanja ukazuju i na povišen rizik od ishemijske bolesti srca (6) i hronične bubrežne slabosti $(7,8)$. AF je neretko praćena karakterističkim osećajem ubrzanog i nepravilnog rada srca (palpitacije), a moguće su i atipične tegobe poput bola u grudima, nedostatka vazduha, malaksalosti, zamaranja, vrtoglavice i omaglice (9). Prisustvo AF se nepovoljno odražava na funkcionalnu sposobnost i kvalitet života (QoL) obolelih $(10,11)$, a skorašnja istraživanja pokazuju da simptomatska prezentacija AF, kao i QoL obolelih mogu biti povezani sa ishodima lečenja (12). Na primer, kod bolesnika sa asimptomatskom AF, kao i kod bolesnika sa AF i atipičnim simptomima (tj. odustvom palpitacija) utvrđen je viši rizik od moždanog udara (13), nepovoljnih kardiovaskularnih (KV) događaja (infarkt miokarda [IM], srčana slabost) i smrtnog ishoda u poređenju sa bolesnicima koji imaju tipične simptome (14). Utvrđeno je i da je QoL u AF povezan sa ishodima lečenja (12).

Imajući u vidu značaj simptomatske prezentacije AF, Evropsko udruženje kardiologa je usvojilo kategorizaciju simptoma pomoću European Heart Rhythm Association (EHRA) skora kojim lekari procenjuju stepen ispoljenosti tegoba i funcionalnog ograničenja (9). Kako neretko postoji neslaganje između objektivne procene tegoba i utiska bolesnika o težini simptoma, osmišljeni su i upitnici koje popunjavaju sami pacijenti, kakav je Atrial Fibrillation Effect on Quality-of-Life (AFEQT), koji je specifičano sačinjen i validiran kod obolelih od AF (15).

Ciljevi ovog istraživanja su da se primenom AFEQT upitika proceni QoL bolesnika sa AF i da se ispita da li je QoL procenjen upitnikom povezan sa ishodima lečenja tokom jednogodišnjeg kliničkog praćenja.

\section{Materijal i metode}

Istraživanje je sprovedeno kao opservaciona kohortna studija u koju su uključeni bolesnici sa elektrokardiografski dokumentovanom AF lečeni u Klinici za kardiologiju Kliničkog centra Srbije (KCS). U periodu od novembra 2014. do februara 2015. uključeni su bolesnici koji su dobrovoljno pristali da popune AFEQT upitnik preveden na srpski jezik od strane istraživača. AFEQT upitnik se sastoji od 20 pitanja pomoću kojih se procenjuju 4 aspekta QoL: (I) simptomi (4 pitanja), (II) ograničenja u dnevnim aktivnostima i socijalnim kontaktima (8 pitanja), (III) zabrinutost oko posledica AF i primenjene terapije (6 pitanja), i (IV) zadovoljstvo lečenjem (2 pitanja) (15). Odgovori su ocenjeni 7-stepenom Likertovom skalom, a upitnikom je povezan QoL i funkcionalni status u jedinstvenu ocenu - ukupni AFEQT skor koji iznosi od 0 do 100, gde rastući skor odgovara višem QoL i obrnuto. Posebno su određeni skorovi za svaku od 4 kompone- 
Vlajković A. et al. Assesment of the association between quality of life in patients with atrial fibrilation and cardiovascular outcomes during the one-year follow-up. MedPodml 2017, 68(3):8-16

te upitnika gde rastući skorovi (od 0 do 100) odgovaraju manjem opterećenju simptomima, boljem funkcionalnom statusu, manjoj zabrinutosti oko lečenja i većem zadovoljstvu primenjenom terapijom (15).

$\mathrm{Na}$ početku istraživanja kod svih ispitanika prikupljeni su sledeći demografski i klinički podaci: starost, pol, školska sprema, prisustvo gojaznosti (indeks telesne mase $>30 \mathrm{~kg} / \mathrm{m} 2$ ) pušenje (sadašnji pušači), svakodnevno konzumiranje alkoholnih pića, srčani ritam prilikom uključenja (sinusni ritam ili AF), klinički tip AF: novo-otkrivena AF (AF prvi put dokumentovana u toku mesec dana pre uključenja), paroksizmalna $\mathrm{AF}$ (napadi AF trajanja nekoliko sati do 7 dana), perzistentna AF (AF trajanja $>7$ dana koja ne prestaje spontano, potrebna farmakološka ili DC kardioverzija) i permanentna AF (AF produženog trajanja, smatra se da nema mogućnosti za uspostavljanje sinusnog ritma) (9). Izvršena je objektivna procena simptoma u skladu EHRA klasifikacijom, prema kojoj se tegobe kategorizuju na: EHRA I klasu - asimptomatska AF, EHRA II klasu - simptomi blagog stepena koji ne ometaju dnevne aktivnosti, EHRA III klasu - simptomi umerenog stepena koji otežavaju dnevne aktivnosti i EHRA IV klasu - simptomi teškog stepena koji onemogućavaju dnevne aktivnosti (9). Prikupljeni su podaci o KV komorbiditetima, ranijim tromboembolijskim komplikacijama i bolestima drugih organa, uključujući dijabetes melitus, hroničnu opstruktivnu bolest pluća, hroničnu bolest jetre i hroničnu bubrežnu insuficijenciju (klirens kreatinina procenjen Cockroft-Gaultovom jednačinom $<60 \mathrm{~mL} / \mathrm{min} / 1,73 \mathrm{~m} 2$ ) (16). Ehokardiografski je procenjena ejekciona frakcija (EF) leve komore i određen je CHA2DS2-VASc skor (C srčana slabost, $\mathrm{H}$ - hipertenzija, A2 - starost $\geq 75$ godina; $\mathrm{D}$ - dijabetes melitus, S2 - moždani udar/TIA, A - statorst 6574 godina, Sc - ženski pol) (9). Evidentirani su i podaci o pristupu lečenju AF - kontrolom srčanog ritma (nastojanje da se farmakološkim i nefarmakološkim merama uspostavi i održi sinusni ritam) ili kontrolom srčane frekvencije (primena lekova za usporavanje srčane frekvencije bez nastojanja da se uspostavi sinusni ritam), kao i podaci o ranijoj DC kardioverziji, ablaciji AF ili ablaciji atrioventrikularnog (AV) čvora. Evidentirani su primenjeni KV lekovi.

Ispitanici su tokom narednih godinu dana praćeni putem kardioloških kontrolnih pregleda u Klinici za kardiologiju KCS obavljenih na 3, 6 i 12 meseci od uključenja u studiju, zaključno sa martom 2016. godine. Na osnovu kliničkog nalaza i medicinske dokumentacije, prilikom kontrola dokumentovani su ishodi studije: 1) značajni KV događaj, definisan kao kombinovani ishod koji uključuje moždani udar/tranzitorni ishemijski atak, IM, perkutanu/hiruršku koronarnu revaskularizaciju ili KV smrt, 2) hospitalizacija zbog simptomatske srčane insuficijencije. Moždani udar je definisan kao neutraumatski, naglo nastali fokalni neurološki deficit trajanja $\geq 24 \mathrm{~h}$; tranzitorni ishemijski atak kao neurološki deficit istih karakteristika trajanja $<24$ h. IM je definisan u skladu sa definicijom usvojenom od strane Radne grupe relevantnih kardioloških udruženja (17). KV smrt je definisana kao smrtni ishod usled akutnog infarka miokarda, srčane slabosti, naprasne srčane smrti, moždanog udara, KV procedure ili posledičnog krvarenja (18). Podaci o smrtnom ishodu su dobijeni uvidom u medicinsku dokumentaciju (npr. otpusna lista) koja je priložena od strane rodbine preminulog. Hospitalizacija zbog srčane insuficijencije je definisana kao hospitalizacija zbog kombinacije karakterističnih simptoma (npr. dispneja, malaksalost), kliničkih i radiografskih znakova kongestije i porasta biomarkera miokardnog stresa (npr. B-tip natriuretskog peptida) (18).

\section{Statistična analiza}

Statistička analiza je obavljena primenom programa IBM SPSS Statistics 22. Numeričke varijable su prikazane kao aritmetička sredina sa standardnom devijacijom, ako su zadovoljeni uslovi normalne raspodele, odnosno kao medijana sa interkvartilnim opsegom (IQR), u slučaju da uslovi normalne raspodele nisu ispunjeni nakon Kolmogorov-Smirnof testa. Kategorijski podaci su prikazani kao apsolutni brojevi sa procentima. Analiza povezanosti QoL (ukupnog AFEQT skora) sa objektivnom procenom težine tegoba (EHRA klasa) izvršena je primenom Spearman-ove korelacije. Procena povezanosti QoL na osnovu ukupnog AFEQT skora i AFEQT skorova za 4 komponete upitnika (simptome, dnevnu aktivnost, zabrinutost i zadovoljstvo terapijom) sa ishodima istraživanja (značajni KV događaji i hospitalizacija zbog srčane slabosti) je izvršena primenom univarijantne logističke regresione analize. AFEQT skor je prvo analiziran kao kontinuirana varijabla, a u slučaju statistički značajne povezanosti, kategorizovan je na kvartile. Povezanost demografskih i kliničkih karakteristika sa ishodima istraživanja je takođe analizirana logističkom regresionom analizom. Varijable statistički značajno povezane sa ishodima studije analizirane su u multivarijantnoj linearnoj regresionoj analizi sa forward uključivanjem varijabli na osnovu čega su određeni multivarijantni prediktori ishoda studije. Regresionim analizom određen je odnos verovatnoće (Odds Ratio, OR), sa pripadajućim $95 \%$ intervalima porevenja (Confidence Interval, CI), a statistička značajnost razlike je definisana nivoom verovatnoće $\mathrm{P}<0,05$.

\section{Rezultati}

Demografske i kliničke karakteristike učesnika istraživanja

Demografske i kliničke karakteristike učesnika su prikazane u Tabeli 1. Uključena su 202 bolesnika sa AF (srednja starost: 64,5 $\pm 12,4$ godina; $62,9 \%$ muškarci). Kliničke karakteristike AF i pridruženi komorbiditeti navedeni su u Tabeli 1. Prema EHRA klasifikaciji, 24,3\% bolesnika su imali asimptomatsku AF (I EHRA klasa), dok su ostali imali simptomatsku AF. Terapijski pristup i KV lekovi su prikazani u Tabeli 2.

Procena kvaliteta života AFEQT upitnikom i korelacija sa objektivnom procenom težine simptoma

Grafik 1 prikazuje srednje vrednosti ukupnog 
Vlajković A. et al. Assesment of the association between quality of life in patients with atrial fibrilation and cardiovascular outcomes during the one-year follow-up. MedPodml 2017, 68(3):8-16

Tabela 1. Demografske i kliničke karakteristikePodaci su prikazani kao srednja vrednost (standardna devijacija), medijana (IQR) ili $\mathrm{n}(\%)$.

\section{DEMOGRAFSKE I KLINIČKE KARAKTERISTIKE}

\begin{tabular}{|c|c|}
\hline Starost & $64,5(12,4)$ \\
\hline \multicolumn{2}{|l|}{ Pol } \\
\hline Ženski pol & $75(37,1)$ \\
\hline Muški pol & $127(62,9)$ \\
\hline \multicolumn{2}{|l|}{ Školska sprema: } \\
\hline Osnovna škola & $35(17,3)$ \\
\hline Srednja škola & $87(43,1)$ \\
\hline Viša škola/fakultet & $82(40,6)$ \\
\hline Indeks telesne mase $\left(\mathrm{kg} / \mathrm{m}^{2}\right)$ & $27,3(3,9)$ \\
\hline Gojaznost (indeks telesne mase $\geq 30 \mathrm{~kg} / \mathrm{m} 2$ ) & $44(21,8)$ \\
\hline Pušači & $28(13,9)$ \\
\hline Svakodnevno konzumiranje alkoholnih pića & $14(6,9)$ \\
\hline \multicolumn{2}{|l|}{ KLINIČKE KARAKTERISTIKE AF } \\
\hline \multicolumn{2}{|l|}{ Srčani ritam pri uključenju: } \\
\hline $\mathrm{AF}$ & $95(47.0)$ \\
\hline Sinusni ritam & $107(53,0)$ \\
\hline Novo-otkrivena AF & $52(25,7)$ \\
\hline Paroksizmalna AF & $109(54,0)$ \\
\hline Perzistentna AF & $32(15,8)$ \\
\hline Permanentna AF & $60(29,7)$ \\
\hline \multicolumn{2}{|l|}{ EHRA klasa: } \\
\hline I & $49(24,3)$ \\
\hline II & $72(35,6)$ \\
\hline III & $67(33,2)$ \\
\hline IV & $14(16,9)$ \\
\hline
\end{tabular}

PRIDRUŽENE BOLESTI

Arterijska hipertenzija

Dijabetes melitus

Hiperlipoproteinemija

Infarkt miokarda

Angina pectoris

Periferna arterijska bolest

Srčana insuficijencija

Bolest srčanih zalistaka

Dilatativna kardiomiopatija

Hipertrofična kardiomiopatija

Ejekciona frkacija leve komore (\%)

Raniji moždani udar ili TIA

Hronično oboljenje jetre

HOBP

HBI (CrCL $<60 \mathrm{~mL} / \mathrm{min})$

Hipertireoidizam

Hipotireoidizam

$\mathrm{CHA}_{2} \mathrm{DS}_{2}$-VASc tromboembolijski skor

\begin{tabular}{|l}
\hline $164(81,2)$ \\
\hline $29(14,4)$ \\
$96(47,5)$ \\
\hline $29(14,4)$ \\
\hline $19(9,4)$ \\
\hline $5(2,5)$ \\
\hline $37(18,3)$ \\
\hline $31(15,3)$ \\
\hline $18(8,9)$ \\
\hline $3(1,5)$ \\
\hline $57,9(9,9)$ \\
\hline $21(10,4)$ \\
\hline $3(1,5)$ \\
\hline $7(3,5)$ \\
\hline $41(20,3)$ \\
\hline $5(2,5)$ \\
\hline $21(10,4)$ \\
\hline $2,7(1,7)$ \\
\hline
\end{tabular}

AF - atrijalna fibrilacija; EHRA - European Heart Rhythm Association; TIA - tranzitorni ishemijski atak; HOBP - hronična opstruktivna bolest pluća; HBI - hronična bubrežna slabost; $\mathrm{CrCl}$ - kliren kreatinina; CHA2DS2-VASc: C - srčana slabost, $\mathrm{H}$ - hipertenzija, A2 - starost $\geq 75$ godina; D - dijabetes melitus, S2 - moždani udar/TIA, A - statorst 65-74 godina, Sc - ženski pol 
Vlajković A. et al. Assesment of the association between quality of life in patients with atrial fibrilation and cardiovascular outcomes during the one-year follow-up. MedPodml 2017, 68(3):8-16

Tabela 2. Terapijski pristup i primenjeni lekovi

\begin{tabular}{|c|c|}
\hline TERAPIJSKI PRISTUP & $\mathrm{N}=202$ \\
\hline Kontrola srčanog ritma & $136(67,3)$ \\
\hline Kontrola frekvencije & $64(31,7)$ \\
\hline DC kardioverzija AF & $35(17,3)$ \\
\hline Ablacija AF & $17(8,4)$ \\
\hline Ablacija atrioventrikularnog čvora & $1(0,5)$ \\
\hline \multicolumn{2}{|l|}{ MEDIKAMENTNA TERAPIJA } \\
\hline Beta-blokatori & $103(51,0)$ \\
\hline Digoksin & $19(9,4)$ \\
\hline Nedihidropiridinski Ca2+ antagonisti & $22(10,9)$ \\
\hline Propafenon & $44(21,8)$ \\
\hline Sotalol & $2(1)$ \\
\hline Amiodaron & $87(43,1)$ \\
\hline ACE inhibitori/Antagonisti AT1 receptora & $142(70,3)$ \\
\hline Dihidropiridinski Ca2+ antagonisti & $62(30,7)$ \\
\hline Diuretici Henleove petlje & $62(30,7)$ \\
\hline Tiazidni diuretici & $68(33,8)$ \\
\hline Spironolakton & $51(25,2)$ \\
\hline Statini & $88(43,6)$ \\
\hline Aspirin & $29(14,4)$ \\
\hline Klopidogrel & $9(4,5)$ \\
\hline Antagonisti vitamina $\mathrm{K}$ & $48(23,8)$ \\
\hline Direktni oralni inhibitori II ili X faktora koagulacije & $37(18,3)$ \\
\hline
\end{tabular}

Podaci su prikazani kao srednja vrednost (standardna devijacija), medijana (IQR) ili n (\%).

DC - direct current; AF - atrijalna fibrilacija; ACE - angiotenzin-konvertujući enzim; AT1 - angiotenzin1

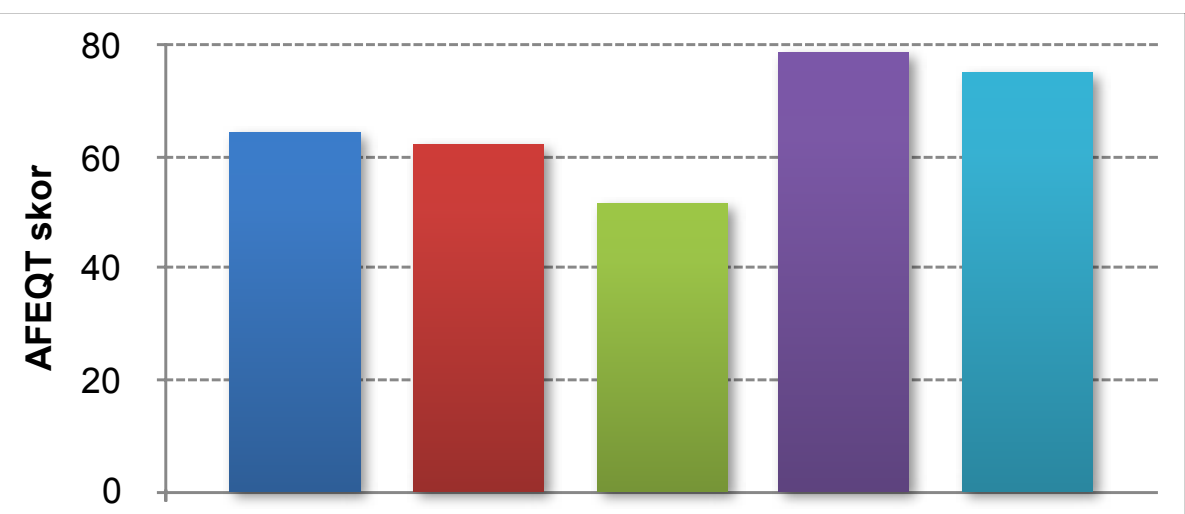

\section{Ukupni AFEQT Simptomi Dnevna aktivnost Zabrinutost Zadovoljstvo}

\section{$64,3 \pm 18,8$}

\section{$62,4 \pm 24,1 \quad 51,6 \pm 29,3 \quad 78,9 \pm 20,5$}

$75,2 \pm 22,4$

Grafik 1. Ukupni AFEQT skor i komponente AFEQT skora - simptomi, ograničenje aktivnosti, zabrinutost zbog posledica aritmije i primenje terapije, zadovoljsto lečenjem

AFEQT skora i srednje vrednosti skorova za komponente procene QoL. Srednja vrednost ukupnog AFEQT skor bila je $64,3 \pm 18,8$ (od maksimalnih 100). Najniže su ocenjeni uticaj AF na aktivnosti $(51,6 \pm 29,3)$ i simptome $(62,4 \pm$ 24,1). Nasuprot tome, ispitanici nisu iskazali veću zabrinutost zbog mogućih posledica lečenja $(78,9 \pm 20,5) \mathrm{i}$ iskazali su prilično zadovoljstvo sprovedenim lečenjem $(75,2$ $\pm 22,4)$.
Pokazana je značajna negativna korelacija između EHRA klase i ukupnog AFEQT skora (Spearman rho = $-0,489, \mathrm{P}<0,001)$. Distribucija vrednosti ukupnog AFEQT skora prema EHRA kategorijama je prikazana na Grafiku 2. 
Vlajković A. et al. Assesment of the association between quality of life in patients with atrial fibrilation and cardiovascular outcomes during the one-year follow-up. MedPodml 2017, 68(3):8-16

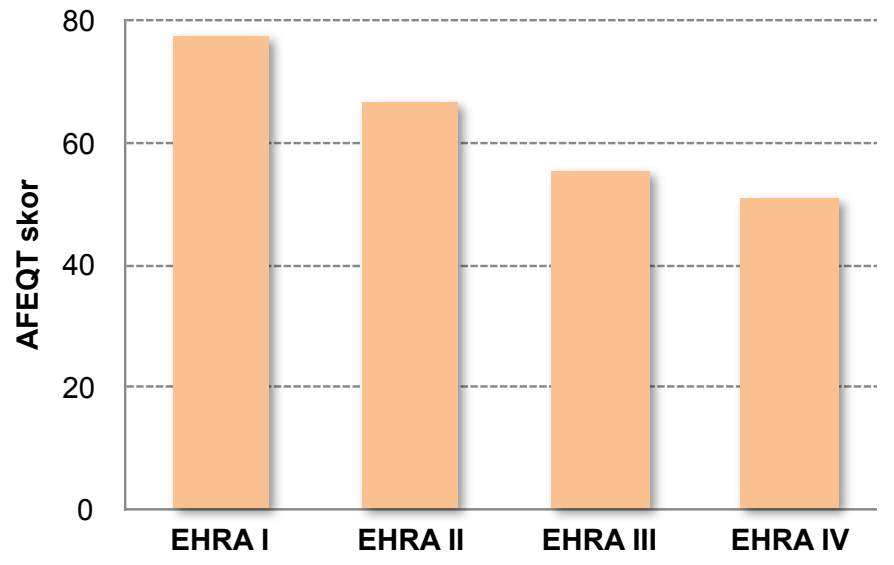

Grafik 2. Distribucija vrednosti AFEQT skora prema EHRA klasi

Povezanost procene kvaliteta života primenom AFEQT upitnika sa ishodima istraživanja

Podaci za definisane ishode istraživanja bili su dostupni za sve ispitanike $(\mathrm{n}=202)$ tokom jednogodišnjeg perioda praćenja. Prvi ishod istraživanja - značajan KV događaj zabeležen je kod $17(8,4 \%)$ ispitanika, od čega je kod $1(0,5 \%)$ registrovan moždani udar, $4(2,0 \%)$ je doživelo IM, kod $6(3,0 \%)$ je sprovedena revaskularizacija (perkutana revaskularizacija - 4; hirurška revaskularizacija - 2), a $6(3,0 \%)$ je umrlo usled KV uzroka. Drugi ishod istraživanja - hospitalizacija zbog srčane insuficijencije, registrovan je kod 7 (3,5\%) ispitanika.

Klinički prediktori značajnog KV događaja prikazani su u Tabeli 3. Ukupni AFEQT skor nije bio statistički značajno povezan sa pojavom značajnog KV događaja. Međutim, skor kojim je procenjeno zadovoljstvo terapijom bio je statistički značajno povezan sa KV događajem, kako u univarijantnoj logističkoj regresionoj analizi (OR, 0,94; 95\% CI, 0,89 - 0,99), tako i u multivarijantnom regresionom modelu (OR, 0,97; 95\% CI, 0,94 - 0,99), oba $\mathrm{P}<0,05$ (Tabela 3). Bolesnici u najvišem kvartilu ocene zadovoljstva terapijom $(\mathrm{n}=45$, skor $>91,7)$ imali su znatno nižu verovatnoću $(\mathrm{OR}, 0,58 ; 95 \% \mathrm{CI}, 0,38-0,76 ; \mathrm{P}=0,024)$ da dožive ozbiljan KV događaj u odnosu na bolesnike u najnižem kvartilu ocene zadovoljstva lečenjem $(n=66$, skor $<66,7)$, Tabela 3.

Klinički prediktori hospitalizacije zbog srčane insuficijencije su prikazani u Tabeli 4. Ukupni AFEQT skor je bio značajno povezan sa hospitalizacijom zbog srčane slabosti tokom jednogodišnjeg praćenja, kako u univarijantnom (OR, 0,94; 95\% CI, 0,89 - 0,99), tako i u multivarijantnom regresionom modelu (OR, 0,98; 95\% CI, 0,95 - 0,99), oba $\mathrm{P}<0,05$ (Tabela 4). Bolesnici sa ukupnim AFEQT skorom u najvišem kvartilu ( $n=50$, skor $\geq 80,7) \mathrm{u}$ multivarijantnoj analizi imali su značajno nižu verovatno-

Tabela 3. Logistička regresiona analiza povezanosti kvaliteta života i kliničkih karakteristika sa značajnim kardiovaskularnim događajem

\begin{tabular}{|c|c|c|c|c|}
\hline \multirow{2}{*}{ Karakteristike } & \multicolumn{2}{|c|}{ UNIVARIJANTNA ANALIZA } & \multicolumn{2}{|c|}{ MULTIVARIJANTNA ANALIZA } \\
\hline & OR $(95 \% \mathrm{CI})$ & P vrednost & OR $(95 \% \mathrm{CI})$ & P vrednost \\
\hline Starost & $1,13(1,07-1,20)$ & $<0,001$ & $1,22(1,09-1,37)$ & 0,001 \\
\hline $\begin{array}{l}\text { Asimptomatska AF } \\
(\text { EHRA klasa }=1)\end{array}$ & $2,43(1,00-5,87)$ & 0,048 & --- & ---- \\
\hline Dijabetes mellitus & $4,01(1,51-10,60)$ & 0,005 & $7,40(1,64-13,77)$ & 0,010 \\
\hline $\begin{array}{l}\text { Ishemijska bolest srca } \\
\text { (raniji infarkt miokarda } \\
\text { ili angina pektoris) }\end{array}$ & $8,38(3,31-21,25)$ & $<0,001$ & $7,32(1,30-11,2)$ & 0,002 \\
\hline $\begin{array}{l}\text { Ranija revaskularizacija } \\
\text { (hirurška/perkutana) }\end{array}$ & $5,78(2,25-14,84)$ & $<0,001$ & --- & --- \\
\hline Bolest srčanih zalistaka & $3,61(1,38-9,47)$ & 0,009 & --- & --- \\
\hline Srčana insuficijencija & $5,64(2,24-14,18)$ & $<0,001$ & --- & --- \\
\hline EF leve komore $<40 \%$ & $6,66(2,11-20,99)$ & 0,001 & --- & --- \\
\hline НOBP & $6,56(1,37-31,44)$ & 0,019 & --- & --- \\
\hline $\mathrm{HBI}(\mathrm{CrCl}<60 \mathrm{ml} / \mathrm{min})$ & $4,55(1,83-11,28)$ & 0,001 & --- & --- \\
\hline $\begin{array}{l}\text { Lečenje kontrolom } \\
\text { frekvencije }\end{array}$ & $3,26(1,34-7,91)$ & 0,009 & --- & --- \\
\hline $\mathrm{CHA}_{2} \mathrm{DS}_{2}-\mathrm{VASc}$ skor & $2,25(1,62-3,14)$ & $<0,001$ & $2,11(1,41-3,11)$ & 0,001 \\
\hline $\begin{array}{l}\text { AFEQT skor za } \\
\text { zadovoljstvo terapijom }\end{array}$ & $0,97(0,96-0,99)$ & 0,012 & $0,97(0,94-0,99)$ & 0,022 \\
\hline $\begin{array}{l}\text { AFEQT skor za } \\
\text { zadovoljstvo terapijom } \\
\text { (IV kvartil vs. I kvartil) }\end{array}$ & $0,54(0,31-0,78)$ & 0,012 & $0,58(0,38-0,76)$ & 0,024 \\
\hline
\end{tabular}

OR - Odds Ratio, CI - interval poverenja; AF- atrijalna fibrilacija; HOBP - hronična opstruktivna bolest pluća; HBI - hronična bubrežna slabosti; CrCl - klirens kreatinina, CHA2DS2-VASc: C - srčana slabost, H - hipertenzija, A2 - starost $\geq 75$ godina; D - dijabetes melitus, S2 - moždani udar/TIA, A - statorst 65-74 godina, Sc - ženski pol; AFEQT - Atrial Fibrillation Effect on Quality of Life 
Vlajković A. et al. Assesment of the association between quality of life in patients with atrial fibrilation and cardiovascular outcomes during the one-year follow-up. MedPodml 2017, 68(3):8-16

ću hospitalizacije zbog srčane slabosti (OR, 0,41; 95\% CI, kvartilu ocene QoL ( $\mathrm{n}=50$, skor $<49,2)$, Tabela 4.

$0,20-0,93 ; \mathrm{P}=0,001) \mathrm{u}$ odnosu na bolesnike u najnižem

Tabela 4. Logistička regresiona analiza povezanosti kvaliteta života i kliničkih karakteristika sa hospitalizacijom zbog srčane slabosti

\begin{tabular}{|c|c|c|c|c|}
\hline \multirow{2}{*}{ Karakteristike } & \multicolumn{2}{|c|}{ UNIVARIJANTNA ANALIZA } & \multicolumn{2}{|c|}{ MULTIVARIJANTNA ANALIZA } \\
\hline & OR $(95 \% \mathrm{CI})$ & P vrednost & OR $(95 \% \mathrm{CI})$ & P vrednost \\
\hline Starost & $1,10(1,01-1,20)$ & 0,024 & $0,98(0,95-0,99)$ & 0,014 \\
\hline $\begin{array}{l}\text { Asimptomatska AF } \\
(\text { EHRA klasa }=1)\end{array}$ & $3,30(1,12-5,10)$ & 0,002 & --- & --- \\
\hline Dijabetes mellitus & $4,87(1,13-13,03)$ & 0,048 & $5,08(1,26-1,32)$ & 0,023 \\
\hline $\begin{array}{l}\text { Ishemijska bolest srca } \\
\text { (raniji infarkt miokarda } \\
\text { ili angina pektoris) }\end{array}$ & $5,51(1,18-15,65)$ & 0,030 & $7,06(1,26-14,53)$ & 0,003 \\
\hline $\begin{array}{l}\text { Ranija revaskularizacija } \\
\text { (hirurška/perkutana) }\end{array}$ & $8,29(3,76-19,13)$ & 0,008 & --- & --- \\
\hline Srčana insuficijencija & $6,64(3,83-10,11)$ & 0,001 & $4,45(2,56-8,36)$ & $<0,001$ \\
\hline EF leve komore $<40 \%$ & $5,60(1,99-11,70)$ & 0,011 & --- & --- \\
\hline HOBP & $5,20(2,35-8,11)$ & 0,004 & --- & --- \\
\hline $\mathrm{HBI}(\mathrm{CrCl}<60 \mathrm{ml} / \mathrm{min})$ & $2,06(1,07-7,20)$ & 0,005 & --- & --- \\
\hline $\mathrm{CHA}_{2} \mathrm{DS}_{2}$-VASc skor & $2,74(1,62-5,04)$ & 0,001 & --- & --- \\
\hline Ukupni AFEQT skor & $0,94(0,89-0,99)$ & 0,011 & $0,98(0,95-0,99)$ & 0,014 \\
\hline $\begin{array}{l}\text { Ukupni AFEQT skor } \\
\text { (IV kvartil vs. I kvartil) }\end{array}$ & $0,39(0,15-0,97)$ & 0,002 & $0,41(0,20-0,93)$ & 0,001 \\
\hline
\end{tabular}

OR - Odds ratio; CI - interval poverenja; EHRA - European Heart Rhythm Association; HOBP - hronična opstruktivna bolest pluća; $\mathrm{HBI}$ - hronična bubrežna slabost, $\mathrm{CHA}_{2} \mathrm{DS}_{2}$-VASc: C - srčana slabost, $\mathrm{H}$ - hipertenzija, A2 - starost $\geq 75$ godina; $\mathrm{D}$ - dijabetes melitus, S2 - moždani udar/TIA, A - statorst 65-74 godina, Sc - ženski pol; AFEQT - Atrial Fibrillation Effect on Quality of Life

\section{DISKUSIJA}

Ovim istraživanjem koje je uključilo 202 bolesnika sa AF, pokazali smo da oboleli imaju snižen QoL prvenstveno zbog opterećenja simptomima i ograničenja aktivnosti. Utvrđena je korelacija između objektivne procene težine simptoma primenom EHRA klasifikacije i procene težine tegoba od strane pacijenata primenom AFEQT upitnika, kao i da je procena QoL i zadovoljstva lečenjem pomoću AFEQT upitnika povezana sa rizikom od hospitalizacije i sa značajnim KV ishodima tokom jednogodišnjeg prospektivnog kliničkog praćenja.

AFEQT upitnik je posebno sastavljen za procenu QoL obolelih od AF (15) sa validnošću i reproducibilnošću koje nadmašuju slične instrumente $(19,20)$ i zadovoljavajućom korelacijom sa objektivnom klasifikacijom tegoba $(12,21)$. Našim istraživanjem je potvrđena značajna negativna korelacija između rastuće EHRA klase (od I do IV) i opadajuće ocene QoL od strane pacijenata izražene ukupnim AFEQT skorom. Distribucija srednjih vrednosti AFEQT skora prema EHRA klasi bila je poredbena sa rezultatima skorašnjih istraživanja u grupi pacijenata slične starosti i kliničkih karakteristika (12). Korelacija između objektivne procene težine simptoma i percepcije samih pacijenata o težini tegoba potvrđuje valjanost AFEQT upitnika kao instrumenta za procenu QoL obolelih od AF (11). Pored toga, u našem istraživanju je pokazano da je $24,3 \%$ bolesnika klasifikovano u I EHRA klasu što odgovara asimptomatskoj AF, međutim, srednja vrednost ukupnog AFEQT skora ovih ispitanika bila je 77,2 od maksimalnih 100 , što ukazuje na tendenciju potcenjivanja blažih tegoba i funkcionalnog ograničenja od strane lekara, iako se ove smetnje negativno odražavaju na QoL bolesnika. Ovaj nalaz naglašava komplementarni značaj AFEQT upitnika, uz objektivnu klasifikaciju simptoma, kako u kliničkoj praksi, tako i u naučnim istraživanjima.

Analiza komponenata AFEQT skora je pokazala da su ispitanici najveći značaj za sniženje QoL pridali tegobama i ograničenju aktivnosti, što ukazuje na važnost terapijskih mera koje imaju za cilj da se regulacijom srčane frekvencije za vreme AF, kardioverzijom u sinusni ritam ili ablacijom AF koriguju tegobe i poveća tolerancija fizičkog napora (22-24). Sa druge strane, pacijenti nisu izrazili veću zabrinutosti zbog mogućih posledica $A F$ i primenjene terapije i visoko su ocenili zadovoljstvo sprovedenim lečenjem. Moguće je da ovi nalazi odražavaju poverenje u izabrana terapijska rešenja, ali moguće je i da odslikavaju nedovoljno poznavanje rizika od komplikacija AF, što potencira značaj edukacije o prirodi bolesti i principima lečenja (25).

Tokom jednogodišnjeg prospektivnog praćenja, definisani ishodi studije su registrovani kod $11,9 \%$ učesnika, od kojih je $8,4 \%$ bolesnika doživelo značajan KV događaj (moždani udar, IM, koronarna revaskularizacija ili KV smrt), a 3,5\% ispitanika je hospitalizovano zbog srčane insuficijencije. Veoma značajan nalaz ovog istraživa- 
Vlajković A. et al. Assesment of the association between quality of life in patients with atrial fibrilation and cardiovascular outcomes during the one-year follow-up. MedPodml 2017, 68(3):8-16

nja odnosi se na povezanost nižeg zadovoljstva lečenjem i veće verovatnoće ispoljavanja nepovoljnih $\mathrm{KV}$ događaja, kao i na povezanost niže ocene QoL AFEQT upitnikom i veće verovatnoće hospitalizacije zbog srčane insuficijencije. Ove povezanosti su zadržale statističku značajnost i u multivarijantnoj regresionoj analizi nakon kontrole za relevantne kliničke prediktore nepovoljnih $\mathrm{KV}$ ishoda i manifestne srčane insuficijencije. Zanimljivo je da je asimptomatska AF (I EHRA klasa) bila povezana sa oba ishoda u univarijantnoj analizi, što je u skladu sa nalazima ranijih studija koji pokazuju da viši rizik od komplikacija i veći mortalitet kod bolesnika sa asimptomatskom $\mathrm{AF}$ $(13,14,26)$. Međutim, u multivarijantnoj analizi, asimptomatska $\mathrm{AF}$ u ovom istraživanju nije zadržala značajnu povezanost sa definisanim ishodima. Nasuprot tome, veće zadovoljstvo terapijom se izdvojilo kao multivarijantni prediktor niže verovatnoće nepovoljnih KV ishoda, odnosno ispitanici sa najvišom ocenom zadovoljstva sprovedenim lečenjem imali su upola nižu verovatnoću da dožive neki od nepovoljnih KV ishoda u udnosu na ispitanike sa najnižom ocenom. Moguće objašenjenje je da su bolesnici koji su bili zadovoljniji lečenjem ostvarili bolju terapijsku adherenciju i perzistenciju tokom narednih godinu dana, uključujući adekvatnu tromboprofilaksu, primenu antitrombocitnih i drugih KV lekova, što se povoljno odrazilo na sniženje rizika od komplikacija $[27,28]$. Takođe smo pokazali da je viši QoL multivarijantni prediktor nižeg rizika od simptomatske srčane slabosti, odnosno da ispitanici sa najvišim ukupnim AFEQT skorom imaju 60\% manju verovatnoću za ispoljavanje srčane insuficijencije od ispitanika sa najnižom ocenom QoL. Slično našim rezultatima, skorašnja studija je pokazala da je rizik od hospitalizacije zbog pogoršanja osnovne bolesti ili srčane slabosti kod bolesnika sa AF 50\% viši ukoliko je ocena QoL

\section{Literatura}

1. Go AS, Hylek EM, Phillips KA, Chang Y, Henault LE, Selby JV et al. Prevalence of diagnosed atrial fibrillation in adults: national implications for rhythm management and stroke prevention: the AnTicoagulation and Risk Factors in Atrial Fibrillation (ATRIA) Study. JAMA. 2001;285:2370-5.

2. Wolf PA, Abbott RD, Kannel WB. Atrial fibrillation as an independent risk factor for stroke: the Framingham Study. Stroke. 1991;22:983-8.

3. Wang TJ, Larson MG, Levy D, Vasan RS, Leip EP, Wolf PA et al. Temporal relations of atrial fibrillation and congestive heart failure and their joint influence on mortality: the Framingham Heart Study. Circulation. 2003;107:2920-5.

4. Benjamin EJ, Wolf PA, D’Agostino RB, Silbershatz H, Kannel WB, Levy D. Impact of atrial fibrillation on the risk of death: the Framingham Heart Study. Circulation. 1998;98:946-52.

5. O'Neal WT, Qureshi W, Zhang ZM, Soliman EZ. Bidirectional association between atrial fibrillation and congestive heart failure in the elderly. Journal of cardiovascular medicine (Hagerstown, Md). 2016;17:181-6.

6. Soliman EZ, Safford MM, Muntner P, et al. ATrial fibrillation and the risk of myocardial infarction. JAMA Internal Medicine. 2014;174:107-14.

7. Soliman EZ, Prineas RJ, Go AS, Xie D, Lash JP, Rahman M
AFEQT upitnikom niska (12). Moguće je da su bolesnici sa nižim QoL suboptimalno lečeni u pogledu kontrole srčane frekvencije ili terapije komorbidite, što se nepovoljno odražava na rizik od srčane slabosti. Imajući u vidu nepovoljnu prognozu srčane insuficijencije u $\operatorname{AF}(5,29)$ može se smatrati da je identifikacija svih relevantnih pokazatelja povišenog rizika od posebnog kliničkog značaja.

\section{Ograničenja studije}

Osnovno ograničenje ovog istraživanja se odnosi na relativno mali broj učesnika, zbog čega nije bila moguća analiza pojedinačnih KV ishoda, kao ni primena Coxovog regresionog modela proporcionalnog odnosa rizika prilikom statističke analize podataka. Pored toga, ne može se isključiti izvesna pristrasnost prilikom uključenja u istraživanje, imajući u vidu da je uslov za uključenje podrazumevao spremost pacijenta da samostalno popuni AFEQT upitnik, što limitira generalizaciju zaključaka.

\section{Zaključak}

Prisustvo AF se nepovoljno odražava na QoL, prvenstveno zbog opterećenja simptomima i smanjenja funkcionale sposobnosti. Rezultati procene QoL primenom AFEQT upitnika korelišu sa objektivnom procenom težine simptoma i doprinose boljem sagledavanju diskretnih tegoba koje se mogu negativno odraziti na QoL, što ukazuje da je AFEQT upinik validan i komplementaran instrument u proceni tegoba i QoL pacijenata sa AF. Viši QoL i veće zadovoljstvo sprovedenim lečenjem su multivarijantni prediktori niže verovatnoće za ispoljenu srčanu insuficijenciju i nepovoljne KV događaje tokom jednogodišnjeg praćenja, što je od značaja u kliničkoj proceni rizika i sprovođenju odgovarajućeg lečenja.

et al. Chronic kidney disease and prevalent atrial fibrillation: the Chronic Renal Insufficiency Cohort (CRIC). Am Heart J. 2010;159:1102-7.

8. Baber U, Howard VJ, Halperin JL, Soliman EZ, Zhang X, McClellan W et al. Association of chronic kidney disease with atrial fibrillation among adults in the United States: REasons for Geographic and Racial Differences in Stroke (REGARDS) Study. Circ Arrhythm Electrophysiol. 2011;4:26-32.

9. Camm AJ, Kirchhof P, Lip GY, Schotten U, Savelieva I, Ernst $S$ et al. Guidelines for the management of atrial fibrillation: the Task Force for the Management of Atrial Fibrillation of the European Society of Cardiology (ESC). Europace. 2010;12:1360-420.

10. Thrall G, Lane D, Carroll D, Lip GY. Quality of life in patients with atrial fibrillation: a systematic review. Am J Med. 2006;119:448.e1-19.

11. Dorian P, Jung W, Newman D, Paquette M, Wood K, Ayers GM, Camm J, Akhtar M, Luderitz B. The impairment of health-related quality of life in patients with intermittent atrial fibrillation: implications for the assessment of investigational therapy. J Am Coll Cardiol. 2000;36:1303-9.

12. Freeman JV, Simon DN, Go AS, Spertus J, Fonarow GC, Gersh BJ et al. Association Between Atrial Fibrillation 
Vlajković A. et al. Assesment of the association between quality of life in patients with atrial fibrilation and cardiovascular outcomes during the one-year follow-up. MedPodml 2017, 68(3):8-16

Symptoms, Quality of Life, and Patient Outcomes: Results From the Outcomes Registry for Better Informed Treatment of Atrial Fibrillation (ORBIT-AF). Circ Cardiovasc Qual Outcomes. 2015;8:393-402.

13. Potpara TS, Polovina MM, Marinkovic JM, Lip GY. A comparison of clinical characteristics and long-term prognosis in asymptomatic and symptomatic patients with first-diagnosed atrial fibrillation: the Belgrade Atrial Fibrillation Study. Int J Cardiol. 2013;168:4744-9.

14. Siontis KC, Gersh BJ, Killian JM, Noseworthy PA, McCabe $\mathrm{P}$, Weston SA et al. Typical, atypical, and asymptomatic presentations of new-onset atrial fibrillation in the community: Characteristics and prognostic implications. Heart Rhythm.13:1418-24.

15. Spertus J, Dorian P, Bubien R, Lewis S, Godejohn D, Reynolds $\mathrm{MR}$ et al. Development and validation of the Atrial Fibrillation Effect on QualiTy-of-Life (AFEQT) Questionnaire in patients with atrial fibrillation. Circ Arrhythm Electrophysiol. 2011;4:15-25.

16. Boriani G, Savelieva I, Dan GA, Deharo JC, Ferro C, Israel $\mathrm{CW}$ et al. Chronic kidney disease in patients with cardiac rhythm disturbances or implantable electrical devices: clinical significance and implications for decision making-a position paper of the European Heart Rhythm Association endorsed by the Heart Rhythm Society and the Asia Pacific Heart Rhythm Society. Europace. 2015;17:1169-96.

17. Thygesen K, Alpert JS, White HD, Jaffe AS, Apple FS, Galvani $\mathrm{M}$ et al. Universal definition of myocardial infarction. Circulation. 2007;116:2634-53.

18. Hicks KA, Tcheng JE, Bozkurt B, Chaitman BR, Cutlip DE, Farb A et al. 2014 ACC/AHA Key Data Elements and Definitions for Cardiovascular Endpoint Events in Clinical Trials: A Report of the American College of Cardiology/American Heart Association Task Force on Clinical Data Standards (Writing Committee to Develop Cardiovascular Endpoints Data Standards). J Am Coll Cardiol. 2015;66:403-69.

19. Ha AC, Dorian P. Health-related quality of life questionnaires: an important method to evaluate patient outcomes in atrial fibrillation ablation. J Interv Card Electrophysiol. 2013;36:177-84; discussion 84.

20. Kotecha D, Ahmed A, Calvert M, Lencioni M, Terwee CB, Lane DA. Patient-Reported Outcomes for Quality of Life Assessment in Atrial Fibrillation: A Systematic Review of Measurement Properties. PLoS One. 2016;11:e0165790.
21. Wynn GJ, Todd DM, Webber M, Bonnett L, McShane J, Kirchhof P et al. The European Heart Rhythm Association symptom classification for atrial fibrillation: validation and improvement through a simple modification. Europace. 2014;16:965-72.

22. Kirchhof P, Breithardt G, Aliot E, Al Khatib S, Apostolakis $S$, Auricchio A et al. Personalized management of atrial fibrillation: Proceedings from the fourth Atrial Fibrillation competence NETwork/European Heart Rhythm Association consensus conference. Europace. 2013;15:1540-56.

23. Bai Y, Bai R, Wu JH, Zhang T, Liu N, Shi XB et al. Differences in Quality of Life Between Atrial Fibrillation Patients with Low Stroke Risk Treated With and Without Catheter Ablation. J Am Heart Assoc. 2015;4:e002130.

24. Sandhu RK, Smigorowsky M, Lockwood E, Savu A, Kaul P, McAlister FA. Impact of Electrical Cardioversion on Quality of Life for the Treatment of Atrial Fibrillation. The Canadian journal of cardiology. 2016.

25. Kirchhof P, Benussi S, Kotecha D, Ahlsson A, Atar D, Casadei B et al. 2016 ESC Guidelines for the management of atrial fibrillation developed in collaboration with EACTS: The Task Force for the management of atrial fibrillation of the European Society of Cardiology (ESC)Developed with the special contribution of the European Heart Rhythm Association (EHRA) of the ESCEndorsed by the European Stroke Organisation (ESO). Eur Heart J. 2016.

26. Boriani G, Laroche C, Diemberger I, Fantecchi E, Popescu MI, Rasmussen LH el al. Asymptomatic atrial fibrillation: clinical correlates, management, and outcomes in the EORP-AF Pilot General Registry. Am J Med. 2015;128:509-18. e2.

27. Spivey CA, Liu X, Qiao Y, Mardekian J, Parker RB, Phatak $\mathrm{H}$ et al. Stroke associated with discontinuation of warfarin therapy for atrial fibrillation. Curr Med Res Opin. 2015;31:2021-9.

28. Weimar C, Cotton D, Sha N, Sacco RL, Bath PM, Weber R et al. Discontinuation of antiplatelet study medication and risk of recurrent stroke and cardiovascular events: results from the PRoFESS study. Cerebrovasc Dis. 2013;35:538-43.

29. Lip GY, Laroche C, Popescu MI, Rasmussen LH, Vitali-Serdoz L, Dan GA et al. Heart failure in patients with atrial fibrillation in Europe: a report from the EURObservational Research Programme Pilot survey on Atrial Fibrillation. European journal of heart failure. 2015;17:570-82. 